\title{
AN OVERVIEW OF ERGONOMICS PROBLEMS RELATED TO CNC MACHINING OPERATIONS
}

\author{
Mohd Hafiz Zani ${ }^{1}$, Isa Halim ${ }^{2}$ and Muhammad Syafiq Syed Mohamed ${ }^{3}$ \\ ${ }^{1,2,3}$ Faculty of Manufacturing Engineering, Universiti Teknikal Malaysia Melaka, Hang Tuah Jaya, \\ 76100 Durian Tunggal, Melaka, Malaysia \\ ahafizzani@gmail.com
}

Keywords: Computer Numerical Control (CNC), Work Related Musculoskeletal Disorder, Muscle Fatigue, Industrial workers, Control measures, Artificial Arm.

\begin{abstract}
.
In the new era of advanced manufacturing technology, machine tool design plays an important role in maximizing productivity and occupational health of industrial workers. However, the machine tool manufacturers face difficulty in designing an ergonomic machine tool that can be suited to Malaysian industrial workers because almost all machine tools were designed according to physical dimensions, capabilities and limitations of European or American populations. This mismatch between machine design and worker abilities may eventually lead to occupational injuries. Therefore, the purpose of this paper is to disseminate information on ergonomics problem, assessment methods, and control measures associated with CNC machining operation. Published articles related to $\mathrm{CNC}$ machining operation have been reviewed. Based on published researches, work-related musculoskeletal disorders such as low-back pain, neck and shoulder problem have been identified as common health problems associated with the machine operation. Engineering and administrative controls have been proposed to minimize the health problems.
\end{abstract}

\section{Introduction}

Nowadays, the industrial has step forward by introduced the advance manufacturing technology, including the Computer Numerical Control (CNC) machines [1, 2]. Since the CNC machines are developed by the European countries and the machines dimensions are based on European population, there is a difficulty for Asian workers to suit the machine design. There is a need to apply Asian anthropometry in the design of CNC machines so that they can work with the machine in safe working posture [3, 4]. The improvement of machine tools design can be viewed from different perspectives such as working posture, muscles activity and oxygen consumption of the workers $[5,6]$. By considering ergonomics principles in the design of CNC machines, the operators can work in safe and productive conditions $[7,8]$.

\section{Related works}

Previous researchers have studied the ergonomics issues in the design of CNC machines, as summarized in Table 1. 
Table 1: Studies on ergonomics issues related to CNC machines

\begin{tabular}{|l|l|l|l|}
\hline \multicolumn{1}{|c|}{ Research Works } & \multicolumn{1}{|c|}{ Focus of Research } & \multicolumn{1}{|c|}{ Methods } & \multicolumn{1}{c|}{ Findings } \\
\hline Khan, I. A., 2012 [2]. & $\begin{array}{l}\text { Ergonomics design of } \\
\text { operators and CNC } \\
\text { machine interface. }\end{array}$ & $\begin{array}{l}\text { Job analysis, } \\
\text { observation and } \\
\text { interview with } \\
\text { operators. }\end{array}$ & $\begin{array}{l}\text { The level of angle of } \\
\text { viewing has significant } \\
\text { effect on CNC } \\
\text { machine operators. }\end{array}$ \\
\hline $\begin{array}{l}\text { Seppala, P. \& } \\
\text { Touminen, E., } 1992 \\
\text { [9]. }\end{array}$ & $\begin{array}{l}\text { Job characteristics and } \\
\text { physical well-being } \\
\text { experienced by CNC } \\
\text { machine operators. }\end{array}$ & $\begin{array}{l}\text { Job analysis, interview } \\
\text { with operators and } \\
\text { questionnaire survey. }\end{array}$ & $\begin{array}{l}\text { CNC machine } \\
\text { operators experienced } \\
\text { troubles in the low } \\
\text { back, shoulders and } \\
\text { neck. }\end{array}$ \\
\hline $\begin{array}{l}\text { Muthukumar, K. et al., } \\
\text { 2012 [10]. }\end{array}$ & $\begin{array}{l}\text { Investigation of } \\
\text { postural discomfort } \\
\text { among CNC machine } \\
\text { operators. }\end{array}$ & $\begin{array}{l}\text { Questionnaire survey } \\
\text { by using Corlett and } \\
\text { Bishop's map. }\end{array}$ & $\begin{array}{l}\text { Neck discomfort due } \\
\text { to the machine display. } \\
\text { Shoulder and arm } \\
\text { discomfort caused by } \\
\text { panel controller. }\end{array}$ \\
\hline $\begin{array}{l}\text { Macias, A. M. et al., } \\
\text { 2009 [11]. }\end{array}$ & $\begin{array}{l}\text { Apply anthropometric } \\
\text { and ergonomics } \\
\text { principles in CNC } \\
\text { work station. }\end{array}$ & $\begin{array}{l}\text { Video recording and } \\
\text { Rapid Entire Body } \\
\text { Assessment (REBA) to } \\
\text { identify and evaluate } \\
\text { stressful posture. }\end{array}$ & $\begin{array}{l}\text { Trunk is the most } \\
\text { affected body part, } \\
\text { followed by legs. }\end{array}$ \\
\hline $\begin{array}{l}\text { Vieira, E.R. \& Kumar, } \\
\text { S., 2007 [12]. }\end{array}$ & $\begin{array}{l}\text { Reduce work-related } \\
\text { low back disorders } \\
\text { among CNC machine } \\
\text { workers. }\end{array}$ & $\begin{array}{l}\text { Epidemiological study, } \\
\text { questionnaire survey } \\
\text { (10-point body part } \\
\text { index, Borg's scale and } \\
\text { visual analogue scale). }\end{array}$ & $\begin{array}{l}\text { CNC workers reported } \\
\text { discomfort in the } \\
\text { lower back. }\end{array}$ \\
\hline
\end{tabular}

\section{Ergonomics risk factor}

Unorganized CNC machine working environment which does not meet the human capabilities is considered as a major source of stress and errors [3,9]. The positioning of control panel and display are very important in CNC machines to reduce the difficulty due to static posture and to prevent work-related musculoskeletal disorders (WMSDs) [10, 11]. During operation, operators were engaged for small periods of time at the controls and continual time monitoring the displays, and expose to the task that cause awkward posture such as clamping and set-up the work piece. Bending, twisting, lifting heavy weight, repetitive movements, static work and making forceful movements were shown to be related to work-related low back disorders $[12,13]$.

\section{Work-related musculoskeletal disorders (WMSDs)}

Work-related musculoskeletal disorders (WMSDs) are diseases related to work that can affect the upper limb extremities, the lower back area, and the lower limbs [14, 15]. WMSDs describe a wide range of disorders and resulted in pain and muscle fatigue for the neck, shoulders, elbows, forearms wrist and hand. WMSDs are main contributors to worker disability and absenteeism in many occupational groups $[16,17]$. Previous studies found that there was a $4 \%$ to $5 \%$ decrease in work productivity for each $10 \%$ limitation increase due to WMSDs [18]. Several factors have been associated with WMSDs such as repetitive motion, excessive force, awkward and/or sustained postures, prolonged sitting and standing [19]. WMSDs are diseases related by work that can affect the upper limb extremities, the lower back area, and the lower limbs and it is a common problem in the general population among industrial workers [20]. 


\section{Assessment Methods}

There are several methods can be used to improve the occupational health of workers when they are using CNC machines [21]. In subjective method, comfort survey questionnaire has been developed to obtain the information of pain, psychophysical experience and discomfort among the workers and it is necessary to obtain relevant information or data on task performance, working posture and environment that related to the $\mathrm{CNC}$ machine workers $[2,4,12]$. The Borg Scale (or called Rating Perceived Exertion, RPE) is used to determine the psychophysical experience of CNC machine workers. It is a type of self-report that has been used for decades to assess levels of physical activity and the simple method of monitoring the work activity intensity $[22,23,24]$. RPE has been shown to relate to several physiological variables, including heart rate, ventilation, respiration rate, oxygen uptake, and blood lactate among others [25, 26]. The scale consists of an array of numbers ranging from 0 (no physical exertion at all) to 10 (extremely strong) and it has become the gold standard for the rating of perceived exertion in performing any jobs [27]. Meanwhile, a direct measurement technique includes surface electromyography (sEMG) used to measure muscle activity of workers while performing jobs [28, 29, 30]. It has the ability to measure the electrical activity (voltage and frequency) in the muscle and it indicates the muscle force and fatigue $[31,32,33]$.

\section{Control Measure}

In ergonomics, there are two methods can be applied to minimize the risk of occupational injuries: administrative controls and engineering controls. In administrative controls, work-rest scheduling is the most commonly adopted to minimize the risk of muscle fatigue and disorders. In engineering controls, engineering techniques such the usage of anti-fatigue resistance mat, reposition the machines to provide easy access to all parts of the CNC machine have been proposed to minimize the risk of occupational injuries [11,21,27]. Additionally, the application of robotic arms for reducing physical efforts in CNC machining operation have yet to be studied in detail. Robotic arms may reduce the amount of physical efforts while loading and unloading raw materials from CNC machines. Some of the relevant studies related to the usage of robotic arms can be found mostly in the medical field where surgeons have been using robots to perform delicate surgeries on humans $[34,35,36]$. Similarly, the same idea can be employed for the purpose of CNC machining operations. Fig. 1 and Fig. 2 show the concept of the development of the robotic arm [37].

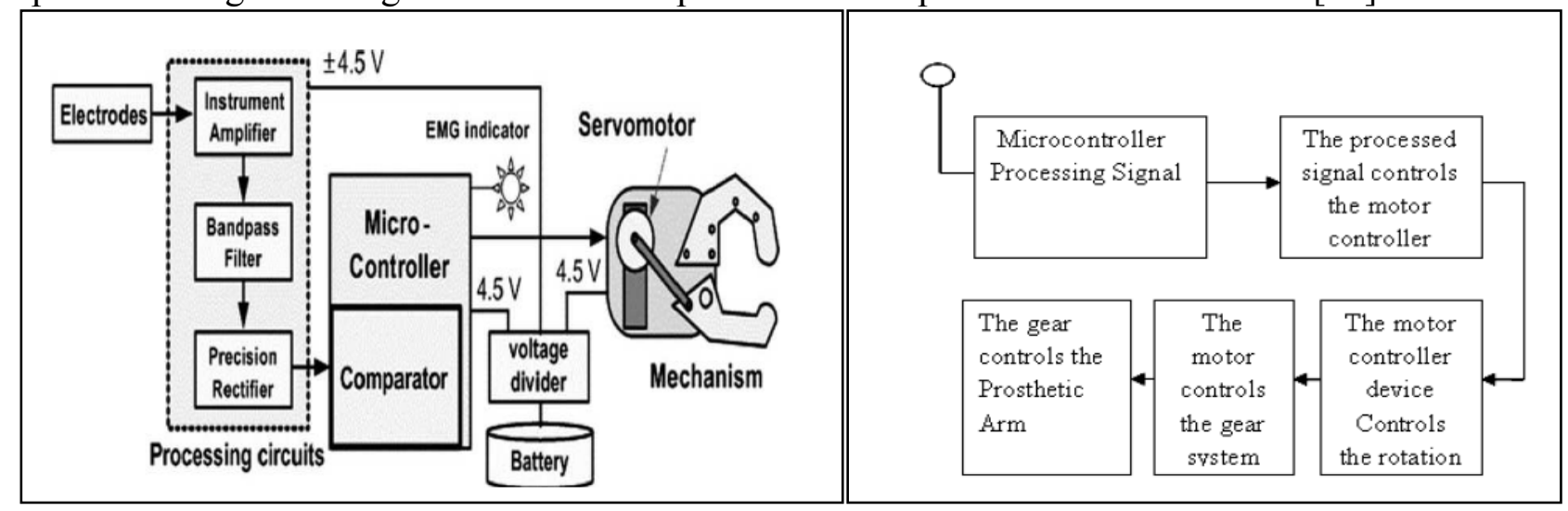

Fig. 1: Movement of the gripper based on sEMG signal [37]

Fig. 2: Movement of robot arm using sensor [37]

\section{Conclusion}

During CNC machining operation, workers exposed to the work related musculoskeletal disorder. Recent studies showed that the factor that lead to the problem were the angle of the view to the control panel and the nature of the task that lead to the awkward posture by the operators. However, these injuries can be minimized through application of engineering and administrative 
controls. This study will look forward in the application of artificial arm in the CNC machining operation that can reduce the risk factor to the workers.

\section{Acknowledgement}

The authors would like to acknowledge the Ministry of Higher Education of Malaysia, the Faculty of Manufacturing Engineering of Universiti Teknikal Malaysia Melaka, the Ministry of Science, Technology and Innovation of Malaysia for funding this research under Research Grant (project no.: RAGS/2012/FKP/TK01/2 B0013), for providing facilities and assistance to prepare this paper.

\section{References}

[1] P. Seppala, E. Touminen, Job characteristics and mental and physical experienced, International Journal of Industrial Ergonomics, 9 (1992) 25-35.

[2] I.A. Khan, (2012) Ergonomics design of Human- CNC machine Human Machine Interaction - Getting Closer, InTech, Available from: http://www.intechopen.com/books/humanmachine-interaction-getting-closer/ergonomic-design-of-human-cncmachine-interface.

[3] B. Das, A.K. Sengupta, Industrial workstation design:A systematic ergonomics approach. Applied ergonomics, 27(3) (1996) 157-163.

[4] J.R. Wilson, Participation - a framework and a foundation for ergonomics? Journal of Occupational psychology, 64 (2001) 67-80.

[5] P.W. Buckle, J.J. Devereux, The nature of work-related neck and upper musculoskeletal disorders. Applied Ergonomics, 33 (2012) 207-217.

[6] Y. Tian, T. Zuo, Ergonomics Research and CNC machine tools in the interface design of the application, Computer-Aided Industrial Design and Conceptual Design 9th International Conference, (2008) 73-77.

[7] M. Iqbal, S.A. Iqbal, A.N.M. Rahman, A.H.M. Samsuzzoha, Ergonomics And Design, Proceedings of the 2011 International Conference on Industrial Engineering and Operations Management Kuala Lumpur, Malaysia, (2011) 22-24.

[8] D. Grayson, A.M. Dale, P. Bohr, L. Wolf, B. Evanoff, Ergonomics evaluation. Part of a Treatment Protocol for Musculoskeletal Injuries, 53 (10) (2005) 450-456.

[9] A. Mitala, A. Pennathur, Advanced technologies and humans in manufacturing workplaces: an interdependent relationship, International Journal of Industrial Ergonomics, 33 (2004) 295-313.

[10] K. Muthukumar, K. Sankaranarayanasamy, A.K. Ganguli, Discomfort analysis in computerized numeric control machine operations. Safety and Health, 3 (2012) 146-153.

[11] A.M. Macias, M.G. Ramirez, J.L. Garcia, J.J. Diaz, S. Noriega, Ergonomic evaluation of work stations related with the operation of advanced manufacturing technology equipement: Two case of study. XV Congreso Internacional De Ergonomica SEMAC, (2009) 1-7.

[12] E.R. Vieira, S.O. Kumar, Occupational risks factors identified and interventions suggested by welders and computer numeric control workers to control low back disorders in two steel companies. International Journal of Industrial Ergonomics, 37 (2007) 553-561. 
[13] I.L. Nunes, P.M. Bush, (2012) Work-Related Musculoskeletal Disorders Assessment and Prevention, Ergonomics - A Systems Approach, InTech, Available from: http://www.intechopen.com/books/ergonomics-a-systems-approach/work-related musculoskeletal disorders assessment and prevention.

[14] B.R. Costa, E.R. Vieira, Risk Factors for Work-Related Musculoskeletal Disorders: A Systematic Review of Recent Longitudinal Studies, American Journal Of Industrial Medicine, (2009) 1-39.

[15] C.R. Reid, P.M. Bush, P. M., W. Karwowski, S.K. Durrani, Occupational postural activity and lower extremity discomfort: A review, International Journal of Industrial Ergonomics, 40 (2010) 247-256.

[16] L. Punnett, D.H. Wegman, Work-related musculoskeletal disorders: the epidemiologic evidence and the debate, Journal of Electromyography and kinesiology, 14 (2004) 13-23.

[17] D. Miller, Effect of Knowledge About Exercise Duration on Ratings of Perceived Exertion and Mood, 6, (2012) 9-13.

[18] R. Escorpizo, Understanding work productivity and its application to work-related musculoskeletal disorders, International Journal of Industrial Ergonomics, 38,(2008) 291297.

[19] B.R. da Costa, E.R Vieira. Risk factor for WRMSDs: A systematic review of Longitudinal Study, American Journal Of Industrial Medicine, 2, (2009) 1-34.

[20] S.A. Moussavi-Najarkola, A. Khavanin, Work related musculoskeletal disorder of the upper limb among steel industry populations Acta Medica Iranica, 45(5), (2006) 405- 414.

[21] I. Halim, A Review On Health Effects Associated With Prolonged Standing In The Industrial Workplaces, IJRRAS, 8 (1), (2011) 14-21.

[22] T.P. Hutchinson, On ratings of comfort and exertion by visual display unit users and ratings of workplace layout and working posture by expert ergonomists, Journal of Applied Ergonomics, 39, (2008) 131-132.

[23] S.G. Karavatas, K. Tavakol, Concurrent validity of Borg's rating of perceived exertion in African-American young adults, employing heart rate as a standard, Internet journal of allied health science and practice, 3(1), (2005) 1-5.

[24] P. Spielholz, Calibrating Borg scale ratings of hand force exertion, Applied Ergonomics, 37, (2006) 615-618.

[25] R.F. Gearhart, J.R. Goss, K.M. Lagally, J.M Jakicic, J. Gallagher, R.J. Robertson, Standardized Scaling Procedures for Rating Perceived Exertion During Resistance Exercise, Journal of Strength and Conditioning Research, 15(3), (2001) 320-325.

[26] E. Hall, P. Ekkekakis, S.J. Petruzzello, Is the relationship of rpe and to psychological dependent?, Official Journal of the American College of Sports Medicine, 5, (2005) 13651373.

[27] A.D. Egan, Sensation Rating of Perceived Exertion During High Intensity and Low Intensity Bouts of Resistance Exercise, UW-L Journal of Undergraduate Research, 4, (2003) 1-6. 
[28] C.I.D. Luca, The use of surface electromyography in biomechanics,Journal Of Applied Biomechanics, 13, (1997) 135-156.

[29] M. González-Izal, A. Malanda, E. Gorostiaga, M. Izquierdo, M. (2012). Electromyographic models to assess muscle fatigue, Journal of Electromyography and Kinesiology, available on: http:// dx.doi.org/10.1016/j.jelekin.2012.02.019.

[30] J. Garza-Ulloa, H. Yu, T. Sarkodie-Gyan, P. Rangel, O. Adeoye, N.V. Hernandez, Mathematical Model To Predict Transition-To-Fatigue During Isometric Exercise On Muscles Of The Lower Extremities, Engineering Supplement: 2012 world Congress on Engineering and Technology, ( 2012) 15-18.

[31] A. Merlo, I. Campanini, Technical Aspects of Surface Electromyography for Clinicians, The Open Rehabilitation Journal, 3, (2010) 98-109.

[32] Y. Yoshitake, M. Miyazaki, Assessment of lower-back muscle fatigue using EMG, MMG and NIRS, 84, (2001) 174-179.

[33] K.A. Henneberg, Principles of electromyography, The Biomedical Engineering Handbook, $2^{\text {nd }}$ edition, CRC Press LLC, Montreal, 3 (2000) 1-12.

[34] J. Palep, Robotic assisted minimally invasive surgery, Journal of minimal access surgery, 5 (2009) 1-7.

[35] M. Anvari, D. Birch, F. Bamehriz, Robotic-assisted laparoscopic colorectal surgery," Surgical Laparoscopy, 14(6) (2004) 311-315.

[36] R. Berguer, W. Smith, An ergonomic comparison of robotic and laparoscopic technique: the influence of surgeon experience and task complexity, Journal of Surgical Research, 134(1) (2006) 87-92.

[37] M.S. Uzer, N.A. Yilmaz, Real-time object tracking by using fuzzy controller for vision-based mobile robot, Scientific Research and Essays, 6(22) (2011) 4808-4820. 